\title{
Kinematic stability analysis of multi-faced rock slopes in the Himalayas
}

\author{
Tarun Singh and KS Rao \\ Indian Institute of Technology- Delhi, \\ New Delhi, India \\ tarun.iitd@outlook.com
}

\begin{abstract}
For the assessment of natural stability of rock slopes, Kinematic analysis technique is extensively used. This technique makes use of dominant discontinuity planes within slope mass to forecast the probability of sliding, wedging and falling. This probability is given in the context of the attitude of slope face which is generally supposed to be of a planar geometry. Such kind of analysis is named as single faced slope (SFS) analysis. Although in nature the probability of finding such simple cases is often less compared to slopes in which the strike direction changes, as in the case of cut slopes; and the slope surface turns to be non-planar. When rock slope surface is either concave or convex shaped, its changing strike also plays an important role in the kinematic analysis (which is generally not used). These slopes will have two or more planar surfaces and are termed as multi-faced slopes (MFS).
\end{abstract}

During the investigation conducted along national highway (NH-21) between District Manali (32014'21'N-77011'43''E) and Village Dundi (32021'25'N-77007'55', E), in the Himalayas; the majority of slopes encountered are MFS. This paper describes the details of kinematic analysis performed on these MFS and gives the stability index for these slopes with the change in strike direction. Three cases are used for the further analysis. Case 1 (Planar sliding), when the failure is based on only one joint set and is planar in nature. Case 2 (Double plane sliding / Wedging), when wedge block is formed and sliding is along both planes, formed by either, the intersection of dominant joint sets or by two slope surfaces. Case 3 (Toppling), when the block topples, either showing flexural toppling or direct toppling. Results of the cases study are presented in this paper.

Keywords-Slope Stability, Kinematic analysis, Multi-faced slopes.

\section{INTRODUCTION}

Kinematic analysis $[1,2]$ is often used to investigate and determine the probability of structurally controlled failures [plane sliding, wedge sliding, and toppling [3]. Slope failure indexing is helpful to model uncertainty and variability and is a powerful tool to quantify the probability of slope failure [4]. For rock slopes containing discontinuities, the uncertainty and variability in rock slope, generally arises from dominating joints and slope face azimuth and the discontinuity strength.

This paper describes the investigation conducted along national highway (NH-21) between Manali District $\left(32^{\circ} 14^{\prime} 21^{\prime \prime} \mathrm{N}-77^{\circ} 11^{\prime} 43^{\prime}, \mathrm{E}\right)$ and Dundi Village $\left(32^{\circ} 21^{\prime} 25^{\prime}\right.$ ' $\left.\mathrm{N}-77^{\circ} 07^{\prime} 55^{\prime} \mathrm{E}\right)$, in the Himalayas. Joint Data Analysis is performed to obtain the values of dominating discontinuities and pole clustering is done using Fisher clustering method. Three cases are considered, Case 1 as Planar sliding, Case 2 as Double plane sliding / Wedging and Case 3 as Toppling. The probability of slope failure is quantified as failure index for each planar, wedge and toppling failure. Stereographic projections are made to determine the failure type and for each failure mode and the total number of discontinuities that cause failure are recorded. The obtained values for left and right Multi Faced Slopes are plotted to understand the effect of dip direction variation on failure modes.

\section{Site LocAtion AND REgional GeOlogy}

Study area lies northern most of Kullu district between latitude $31^{\circ} 53^{\prime} \mathrm{N}$ to $32^{\circ} 25^{\prime} \mathrm{N}$ and longitude $76^{\circ} 48^{\prime} \mathrm{E}$ to $7^{\circ} 29^{\prime} \mathrm{E}$ (Fig. 1) at MSL 3091m in Himachal Pradesh (HP), India. The main sites of the area are Manali $(2000 \mathrm{~m})$, Palchan $(2320 \mathrm{~m})$ and Solang $(2480 \mathrm{~m})$ and Dhundi $(2800$ $\mathrm{m})$, The study area, as well as downstream valley, is drained by Beas River, one of the tributaries of Indus river system, originating from Beas Kund (a small ice body) at an elevation of $4038 \mathrm{~m}$ on the eastern slope of Rohtang pass in the western Himalayas. The area is located in the Lesser Himalayan zone which is bounded by Main Boundary Thrust (MBT) in the south and Main Central Thrust (MCT) in the north. The area exhibits a rugged topography with high hills, deep valley and steep slopes.

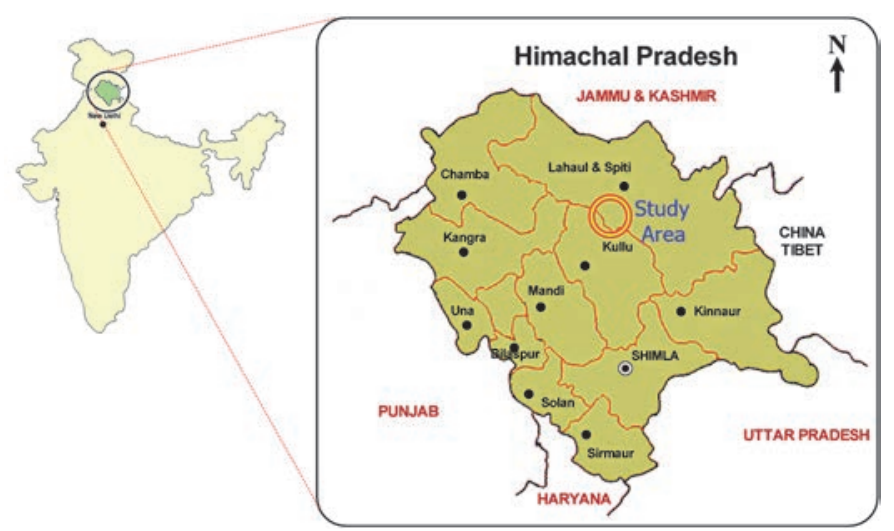

Fig. 1. Location Map of the Project Area

The geology of this area has been studied by various workers [5,6,7] and mapped in detail [8]; A major tectonic 
feature separates the Lahaul-Spiti segment of the SpitiZanskar basin from the Tandi basin and also the ChambaBhadarwah basin and represents crystalline core with doubly plunging disposition. This zone has the elements of mantled gneiss exhibiting anatexis and migmatization and underlies the Infra-Cambrian sediments. The overlying sedimentary sequence and its metamorphosed basal part are welded to the crystalline basement and it forms the root zone area of the Salkhala Nappe. The regional geology of area is presented in Table I.

TABLE I. REGIONAL GEOLOGICAL SUCCESSION AROUND THE AREA

\begin{tabular}{|l|l|}
\hline Rock Formation & Age \\
\hline Tandi Formation (Batal Formation ) & Permian to Jurassic \\
\hline $\begin{array}{l}\text { Salkhala Group (Rohtang Gneissic } \\
\text { Complex) }\end{array}$ & Pre-Cambrian \\
\hline
\end{tabular}

On the right bank of the river, the stretch between the river edge and El $2805 \mathrm{~m}$ the flat topography is covered with riverine terrace deposit. The hill slopes beyond $2805 \mathrm{~m}$ and up to $2900 \mathrm{~m}$ are covered with a thick pile of slope wash material constituted by loose rocks of metabasics. The riverbed material consists of a heterogeneous mixture of Boulders, Cobbles, Pebbles and gravel of various rock types mixed with sandy silt. Boulders up to the size of $1.5 \mathrm{~m}$ have been encountered along with numerous boulders of $80 \mathrm{~cm}$ size at various depth. The variation in size and quantum of boulders viz. a viz. fines encountered in the riverbed is high, indicating large-scale heterogeneity in the material.

\section{JOINT DATA ANALYSIS}

Two slopes are analysed in this study, lying on the left and right bank of River Beas at $32^{\circ} 21^{\prime} \mathrm{N}$ and $77^{\circ} 07^{\prime} \mathrm{E}$. Dip amount and dip direction readings of joints and discontinuities are recorded, both from field and face-logs of the slope. A total of 597 discontinuities readings is used to obtain four dominant joint sets on the left and right slope (area $300 \mathrm{~m} \times 400 \mathrm{~m}$ ). A rose diagram is plotted for collected data to get the dominant directions of joint orientation (Fig. 2 ). Figure 3 shows a density stereogram of all poles of discontinuities made using the fisher distribution contouring method for both left and right slope. The areas having a high concentration of poles are taken on the density stereogram as windows to project a respective joint plane.

For left slope the orientation variability of the major discontinuities is well depicted by the pole windows as shown in density stereogram (Fig. 3(a)). First Joint Set (S1) has azimuth from $066^{\circ}$ to $078^{\circ}$ and in dip amount from $57^{\circ}$ to $67^{\circ}$. Second Joint Set (S2) has azimuth from $310^{\circ}$ to $320^{\circ}$ and in dip amount from $59^{\circ}$ to $71^{\circ}$. Third Joint Set (S3) hasazimuth from $167^{\circ}$ to $177^{\circ}$ and in dip amount from $52^{\circ}$ to $66^{\circ}$. Fourth Joint Set (S4) hasazimuth from $266^{\circ}$ to $275^{\circ}$ and in dip amount from $56^{\circ}$ to $66^{\circ}$. The average of all the discontinuity orientation data is selected and four such joints having an average orientation of windows are mapped as S1, S2, S3 and S4. Table II shows these prominent joint sets for left bank slopes. Prominent strike of the discontinuity plane $\mathrm{S} 1$ is along NNW and SSE.

The persistence of most of these major discontinuities is averaged to be lying in the range of $2 \mathrm{~m}$ and $10 \mathrm{~m}$, the spacing between two planes of same joint set ranges from 30 $\mathrm{cm}$ to $1 \mathrm{~m}$ and the aperture or opening of most discontinuities ranges from $0 \mathrm{~mm}$ (tight) to $5 \mathrm{~mm}$ at some places.

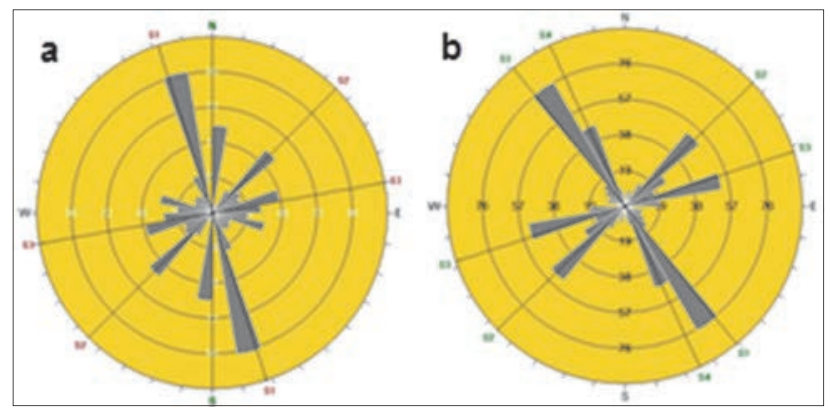

Fig. 2. . Rose Diagram Showing Orientation of Major Joint Planes (S1-S4). A) Rose Diagram for Left Embankment, B) Rose Diagram for Right Embankment

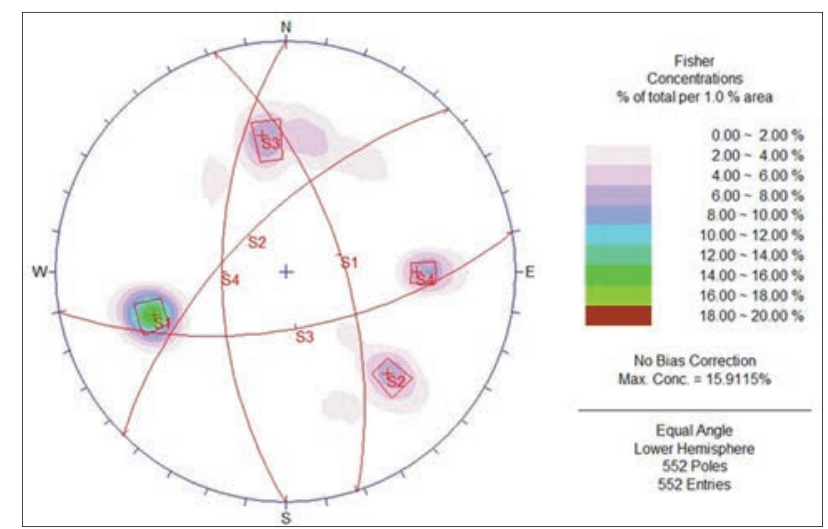

(a)

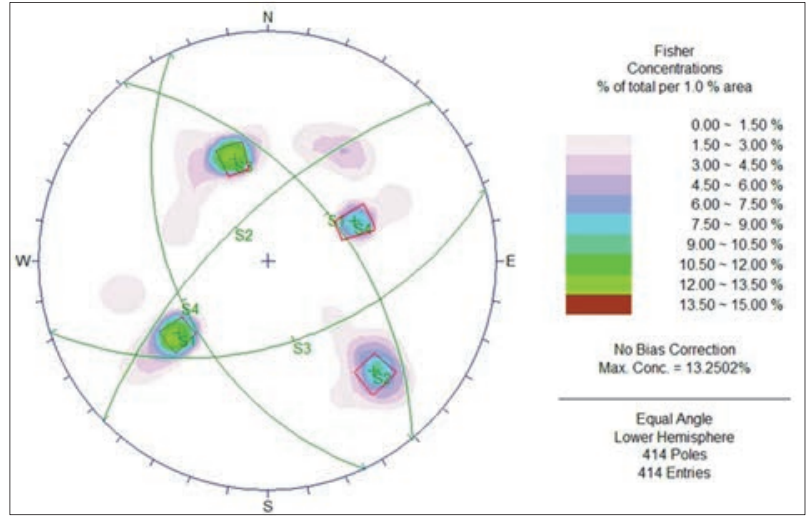

(b)

Fig. 3. Density Stereogram of all Poles of Discontinuities for (a) Left Slope and (b) Right Slope

For right slope the orientation variability of the major discontinuities is well depicted by the pole windows made in density stereogram (Fig 3(b)). First Joint Set (S1) hasazimuth from $045^{\circ}$ to $057^{\circ}$ and in dip amount from $48^{\circ}$ to $59^{\circ}$. Second Joint Set (S2) hasazimuth from $154^{\circ}$ to $169^{\circ}$ and in dip amount from $43^{\circ}$ to $59^{\circ}$. Third Joint Set (S3) haveazimuth from $311^{\circ}$ to $322^{\circ}$ and in dip amount from $63^{\circ}$ to $73^{\circ}$. Fourth Joint Set (S4) have azimuth from $239^{\circ}$ to $254^{\circ}$ and in dip 
amount from $37^{\circ}$ to $52^{\circ}$. The average of all the discontinuity orientation data is selected and four such joints having an average orientation of windows are mapped as S1, S2, S3 and S4.Table III shows these prominent joint sets for right bank slope. Predominant strike direction of the major discontinuity is along NNW and SSE directions.

The persistence of most of these major discontinuities is expected to be between $1 \mathrm{~m}$ and $5 \mathrm{~m}$, the spacing between two planes of same joint set ranges from $30 \mathrm{~cm}$ to $1 \mathrm{~m}$ and the aperture or opening of most discontinuities ranges from $1 \mathrm{~mm}$ to $4 \mathrm{~mm}$ at some places. Most of the discontinuities have moderate dip angles varying from 450 to 670 . For the kinematic analysis the friction angle for metabasic rock is taken as 33o, while for Schist 24o. The above values were obtained from the laboratory test conducted on dry rock samples.

TABLE II. DOMINANT JOINT SETS OF LEFT BANK

\begin{tabular}{|l|l|l|l|}
\hline No & Joint & \multicolumn{1}{|c|}{ Dip-Direction $\left.\mathbf{(}^{\circ}\right)$} & \multicolumn{1}{c|}{ Dip $\left.\mathbf{(}^{\circ}\right)$} \\
\hline 1 & S1 & 072 & 62 \\
\hline 2 & S2 & 315 & 64 \\
\hline 3 & S3 & 170 & 62 \\
\hline 4 & S4 & 270 & 59 \\
\hline
\end{tabular}

TABLE III. DOMINANT JOINT SETS OF RIGHT BANK

\begin{tabular}{|l|l|l|l|}
\hline No & \multicolumn{1}{|c|}{ Joint } & \multicolumn{1}{|c|}{ Dip-Direction $\left(^{(}\right)$} & Dip $\left(^{\circ}\right)$ \\
\hline 1 & S1 & 051 & 53 \\
\hline 2 & S2 & 315 & 67 \\
\hline 3 & S3 & 162 & 50 \\
\hline 4 & S4 & 245 & 45 \\
\hline
\end{tabular}

\section{Result of KinematiC ANALysis}

For the rock slopes investigated at the site, the kinematic analysis is performed for both, left and right slopes to estimate the possibility of slope failure. Three basic slope failure, the Planar failure, the Wedge failure and the Toppling failure are analysed using Rocscience DIPS 7.0 program and Markland tests have been conducted to determine the failure index for each of these failure modes. Slopes on both left and right bank are such that the strike direction varies within short distance and these slopes cannot be represented with one single sloping or dipping direction. Such slopes are termed as Multi Faced Slopes (MFS) and in the area both concave (Right Bank Slope) and convex (Left bank slopes are found to show characteristics of MFS. To kinematicallyanalyse these slopes two separate studies are conducted each for left and right bank slope. Each study is further branched into three independent cases based on failure modes for rock slopes. Case 1 (Planar sliding), when the failure in based on only one joint set and is planar in nature. Case 2 (Double plane sliding / Wedging), when wedge block is formed and sliding is along both planes, formed by either of the intersection of dominating joint sets or by two slope surfaces. Case 3 (Complex Sliding), when the block topples, either showing flexural toppling or direct toppling. For every case, change is strike direction and probability of slope failure is calculated at every $30^{\circ}$ of strike variation.

\section{A. Left Bank Slope}

For left bank slope, variation in the strike is found out to range from $\mathrm{N} 40 \mathrm{oE}$ to $\mathrm{N} 325 \mathrm{oW}$. The slope faces are convex outward and has a high probability of failures, such MFS slope requires sectional analysis. Three sections for this slope are cut at $30 \mathrm{o}$ interval such that their combination represents the complete slope face. For each section, the kinematic analysis is made for planar, wedge and toppling failure. Fig. 4(a) L1 and L2P shows the stereographic projection section 1 and section 2 with four dominant joint planes (S1, S2, S3 and S4) along with changing slope face. Slope failure index namely Plane Failure Index (PFI), Wedge failure Index (WFI) and Toppling Failure Index (TFI) have been calculated for three types of slope failures. Fig. 5(a) L2P,

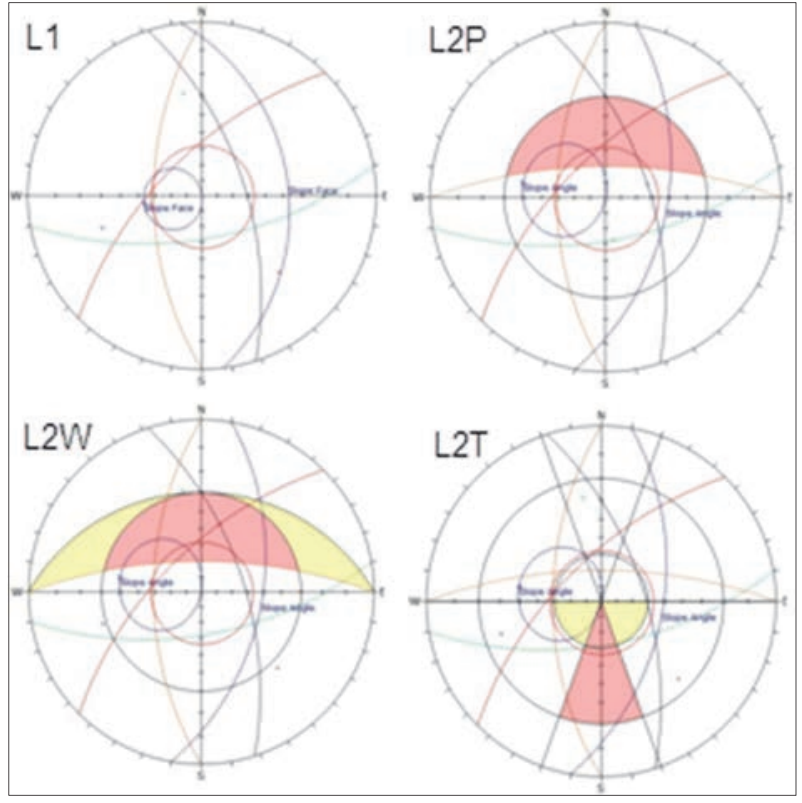

Fig. 4(a). Kinematic analysis of left bank slope

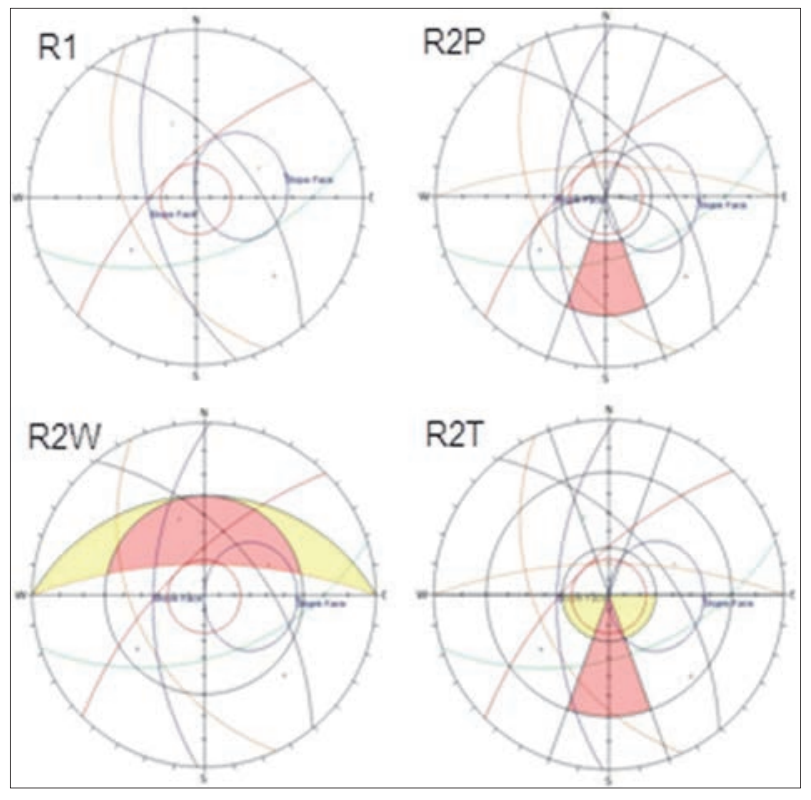

Fig. 4(b). Kinematic analysis of right bank slope 
L2W and L2T shows the kinematic analysis performed for case 1, case 2 and case 3 respectively. Obtained failure index values are plotted in Fig. 4(a) with the change in slope azimuth.

\section{B. Right Bank Slope}

For right bank slope, a variation in the strike is found out to range from $\mathrm{N} 45 \mathrm{oE}$ to $\mathrm{N} 315 \mathrm{oW}$. The slope faces are concave outward and also has a high probability of failures, such MFS slope requires sectional analysis. Three sections for this slope are cut at $30 \mathrm{o}$ interval, such that their combination represents the complete slope face. For each section, the kinematic analysis is made for planar, wedge and toppling failure. Fig. 4(b) R1 and R2P shows the stereographic projection section 1 and section 2 with four dominant joint planes (S1, S2, S3 and S4) along with changing slope face. Slope failure index namely Plane Failure Index (PFI), Wedge failure Index (WFI) and

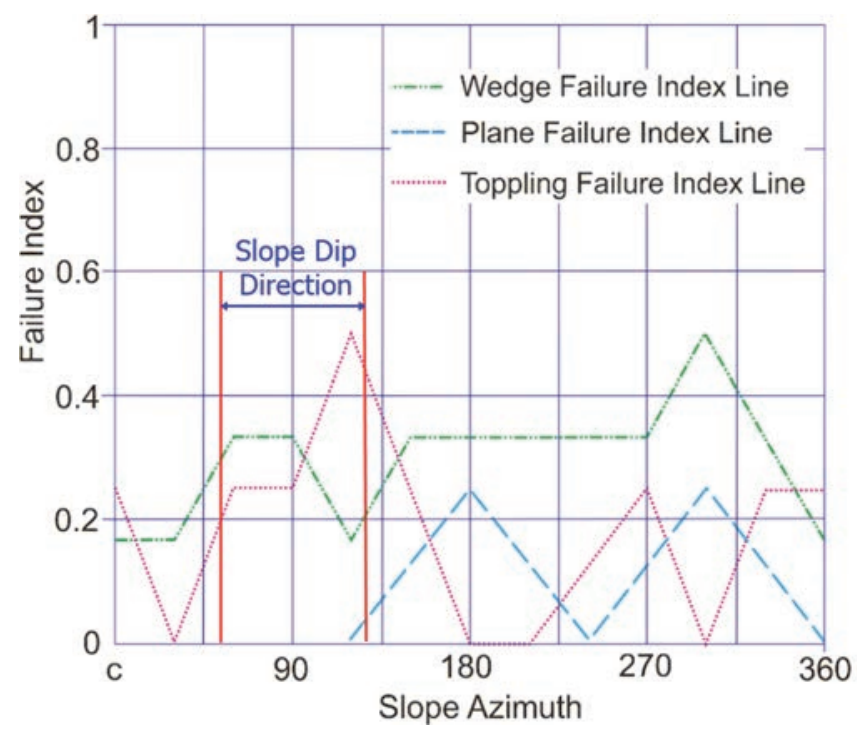

Fig.5(a). Failure Index plot for left bank slopes.

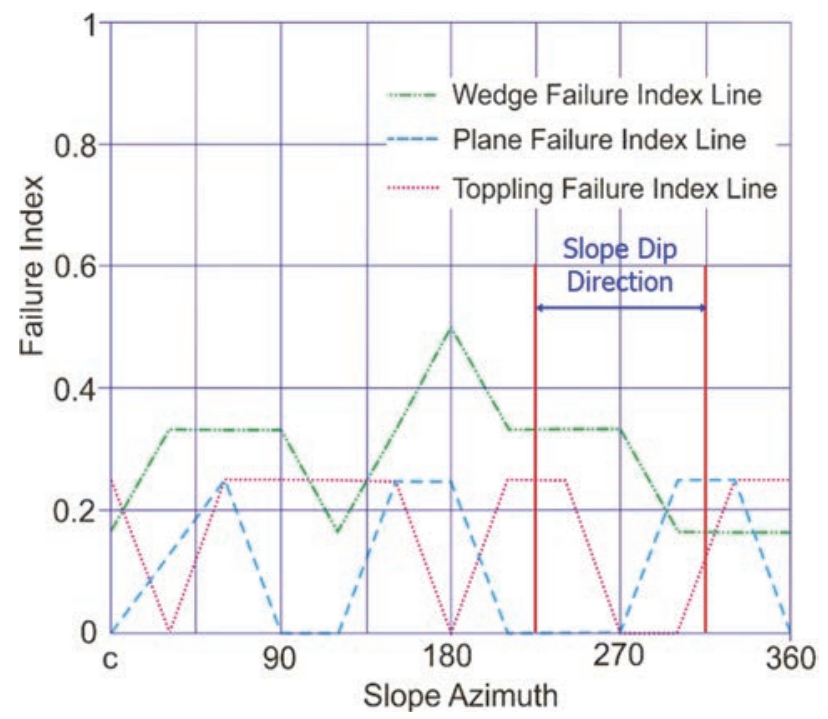

Fig.5(b). Failure Index plot forright bank slopes.
Toppling Failure Index (TFI) have been calculated for three types of slope failures. Fig. 4(a) R2P, R2W and R2T shows the kinematic analysis performed for case 1, case 2 and case 3 respectively. Obtained failure index values are plotted in Fig. 5 (b) along with the change in slope azimuth.

\section{DISCUSSION}

Kinematic analysis [1, 2] along with Markland test [1] is used here to analyse the potential for the various modes of rock slope failures which incur due to the presence of unfavourably oriented discontinuities. Four such unfavourable discontinuities are obtained for left and right bank slope, by performing Joint Data Analysis on recorded discontinuities azimuth using Fisher clustering method. The probability of slope failure is checked with respect to slope face, as the slope face is not constant, on different stereographic projections as per requirement of planar, wedge and toppling failure $[1,2]$ are made to determine a failure type. For each stereographic projection, failure index for Planar, Wedge and Toppling is calculated. Most of the index value obtained are $0.25,0.33$ and 0.5 , which represent that one (planar sliding or toppling), two (wedge failure with sliding on any one joint plane) and two (wedge failure with sliding on two joint planes) discontinuities planes are responsible for failure in that particular direction. The obtained values for left and right bank MFS are plotted in Fig. 5 and are represented by a Dip Direction variation window (arrow). The plot has been further extended to 0o and $360 \mathrm{o}$, strictly for incorporating the effect of dip direction variation on failure modes. For each failure mode failure index values have been calculated and plotted in Fig. 5. This plot, however, will be of great use, if slope undergoes excavation.

\section{REFERENCES}

[1] E. Hoek, and D. Jonathan Bray,. "Rock slope engineering,". CRC Press, 1981.

[2] C.F. Watts, D. Gilliam, M. Hrovatic, and H. Hong, "User's Manual Rockpack III for Windows," Rock slope stability computerized analysis package, part one-stereonet analyses, CF Watts \& Associates, 2003

[3] R.E. Goodman, "Introduction to rock mechanics," 2nd Ed., Wiley,New York., 1989.

[4] G. B. Baecher,and J.T. Christian, "Reliability and statistics in geotechnicalengineering,"John Wiley\& Sons, New York, 2003.

[5] Chandel, B.S. Vishwa, K. Kaur, Brar, and Yashwant Chauhan. "RS \& GIS based landslide hazard zonation of mountainous terrains a study from Middle Himalayan Kullu District, Himachal Pradesh, India." International journal of Geomatics and Geosciences 2, no. 1 (2011): 121.

[6] V. M Choubey, P. K. Mukherjee, B S. Bajwa, and Vivek Walia, "Geological and tectonic influence on water-soil-radon relationship in Mandi-Manali area, Himachal Himalaya." Environmental geology, vol.52(6), pp. 1163-1171, 2006.

[7] Choubey, M. Vinay, K. Kewal. Sharma, and R. C. Ramola, "Geology of radon occurrence around Jari in Parvati valley, Himachal Pradesh, India," Journal of environmental radioactivity, vol. 34(2), pp. 139147, 1997.

[8] V.P. Sharma, “Geology of Kullu-Rampur belt, H. P,”. Mem. Geol. Soc. India, vol. 106, pp. 235-407. 